\title{
Factors influencing the mat forming process via aerodynamic spreading in cement-bonded particleboard production
}

\author{
Martin Direske $^{1} \oplus \cdot$ Jiří Procházka $^{2} \cdot$ Christoph Wenderdel $^{1}$
}

Received: 8 July 2019 / Accepted: 8 October 2020 / Published online: 31 October 2020

(c) The Author(s) 2020

\begin{abstract}
The production of three-layered cement-bonded particleboards (CBPB) differs in most cases from that of adhesively bonded particleboards. However, one production step is quite similar: mat forming. A homogeneous mat is formed by aerodynamic or by mechanical spreading or by a combination of both methods. The distribution of the particles is influenced by their separation and flight characteristics. Those characteristics are in turn influenced by particle size and the combination of the particle's surface area and weight. Because density of cement is higher than that of wood, the cement/wood (c/w) ratio will influence the particles' separation and flight characteristics significantly. In the current study, laboratory-made particles of different sizes were mixed with different amounts of cement. An aerodynamic former was then used to help determine the influence of the different particle types and the $\mathrm{c} / \mathrm{w}$ ratio of the mix on mat forming. The strewn particles were analysed for their distribution of mass, size and cement content as a function of spreading distance. The particle size decreased with increasing spreading distance. In addition, the cement content and spreading distance were positively correlated. For a c/w ratio of 1.9, increasing cement content correlated with increasing distance. This means, large particles and less cement tended to fall earlier than smaller ones and more cement. This corresponds to the observation that the specific surface area of the particles increases with increasing spreading distance. Vice versa, the density of the particles decreases with increasing spreading distance. The effect is more apparent when the particle mixture is heterogeneous in size at constant process parameters (e.g., air velocity). Looking at the density profile of a CBPB board, the surface layers consist of small particles with a higher cement fraction, and the core layer consists of large particles with smaller cement fraction. Thus, the production of CBPB requires two aerodynamic formers working in opposite directions. With the results of this study, it is possible to optimise production parameters, such as the speed of the transport caul and the air velocity with regard to the infeed raw material parameters in order to create a symmetrical particle distribution from top to bottom of the mat, resulting in an optimized and application-oriented density profile.
\end{abstract}

\section{Introduction}

Cement-bonded particleboards (CBPB) are composite materials consisting mainly of wood particles, cement, water and additives. CBPB is currently used in cladding, flooring, roofing material, prefabricated houses, office containers and sound barrier walls (Moslemi 1999; Frybort et al. 2008). The main advantages of CBPB, compared to adhesively

Martin Direske

martin.direske@ihd-dresden.de

1 Institute of Wood Technology Dresden (IHD), 01217 Dresden, Germany

2 Department of Wood Science and Technology, Faculty of Forestry and Wood Technology, Mendel University in Brno, Zemedelska 3, 61300 Brno, Czech Republic bonded wood composites, are CBPB's high stiffness, high dimensional stability, good acoustic properties, very low formaldehyde emissions, high biological decay resistance and fire resistance. In addition, CBPBs have advantages when compared to concrete: They have a comparably low density, and they can be processed with regular wood processing machinery as far as, for example shaping, cutting, drilling and sanding, is concerned (Jorge et al. 2004).

Almost all physical and mechanical properties of woodbased panel products are associated with their density (Plath and Schnitzler 1974; Boehme 1992; Niemz and Sonderegger 2017). The density profile, which is the density perpendicular to the plane of the panel, is especially crucial for board properties. Most of the commercially available wood-based panels typically show a "U-profile", with the peak density near the board's surface, and the 
lowest density in the board's core. The effects of the density profile on the performance of adhesively bonded particleboards (PB) have already been shown. For example, board properties like bending strength, water absorption, dimensional stability and machinability are influenced by the density profile (Boehme 1992; Schulte and Frühwald 1996; Wong et al. 1999). With the density peaks in the outer layers of the boards, high tensile and bending strength and stiffness are achievable. In contrast, the core layer has to withstand transverse and shear forces.

The density profile of adhesively bonded PB is mainly affected by the different particle sizes in the surface and core layers, with larger particles in the core layer, on the one hand, and thermo- and hydrodynamic processes during the hot-pressing process on the other. This results in a heterogeneous density distribution throughout the thickness of the board. For CBPB, another factor influences the shape of the density profile. Because of the high difference in density between wood (spruce $\sim 400 \ldots 500 \mathrm{~kg}$ / $\mathrm{m}^{3}$ ) and cement (Portland cement $3000 \ldots 3100 \mathrm{~kg} / \mathrm{m}^{3}$ ), the composition of the wood-cement mixture has a significant influence. Usually, the cement content is higher in the surface layers than in the core layer. Furthermore, and comparable to adhesively bonded PB, the wood particles in the surface layers are much smaller and have a higher moisture content than those in the core layer (Pampel and Schwarz 1979; Fan et al. 2006; van Elten 2006; Saunders and Davidson 2014).

Typically, the industrial production process of CBPB is divided into six steps (Schwarz et al. 1994; Fan et al. 1999):

1. Mixing wood particles, cement, additives and water,

2. Mat forming one- or three-layered mats,

3. Pressing $1.5 \ldots 3 \mathrm{MPa}$, clamping in a cassette,

4. Curing $60 \ldots 80^{\circ} \mathrm{C}, 6 \ldots 8 \mathrm{~h}$,

5. Conditioning $14 \ldots 28$ days in stack, and

6. Drying $90 \ldots 110^{\circ} \mathrm{C}$, moisture content $6 \ldots 12 \%$.

Step (2), the forming of a consistently uniform mat, is one of the most important steps of the board-manufacturing process. A lack of uniformity in the distribution of particles throughout the mat will result in physical property variations, such as warping, density variations and excessive thickness spring-back of high-density areas (Thoemen et al. 2010). The board density directly affects the board properties. Consequently, the preparation of a mat with consistent density is critical for producing boards with optimised and application-oriented properties.

Three-layered CBPBs are usually produced with fine, dense top layers and a coarser, less dense core layer. In practice, the three-layered structure can be achieved in two ways. The processes take their names from the companies that developed them (van Elten 2006):

\section{The Eltomation Process}

- Preparation of one cement-particle mixture in a large mixer

- Spreading by means of two spreader heads working in opposite directions (mechanical or aerodynamic spreading)

- Fine particles end up in the surface layers

- Coarse particles end up in the core layer

\section{The Bison Process}

- Preparation of two cement-wood mixtures (surface layers and core layer separately)

- Spreading by means of three spreader heads $(2 \times$ surface layer, $1 \times$ core layer)

- Surface layer via aerodynamic spreading

- Core layer via mechanical spreading

One type of forming machine uses the principle of aerodynamic separation to lay graduated or multi-layered mats. This forming station produces a mat with fines in the outer layers of the boards and coarser particles in the core, without distinct layer separation. The effect of the horizontal airflow is to blow the finest particles to the extreme ends of the former, while the coarser particles drop almost vertically (Soiné 1995). The spreading distance of a particle is a function of particle mass and surface area, air velocity, particle acceleration and gravity (Rackwitz and Obermaier 1962).

However, the functional relationships between process parameters and the resulting particle distribution within the mat for CBPB are not yet fully understood. The density profiles of industrial CBPB are usually heterogeneous. Research at the IHD Dresden shows three types of density profiles: "U-shape", "W-shape" and "even-shape". Like PB, some CBPBs show a typical "U-shape", with the peak density near the surface of the board and the lowest density in the core. In certain cases, the density profile of CBPB may show a "W-shape", with an additional peak in the core of the board. The third type is characterised by an evenly distributed density throughout the panel thickness. In contrast to $\mathrm{PB}$, thermo- and hydrodynamic processes during pressing do not influence the shape of the density profile of CBPB. The density profile of CBPB depends on the distribution of the wood-cement mixture across the board thickness. Since the mat forming process controls the distribution, it can be assumed that different profiles may be achieved via different mat forming processes.

The objective of this paper was to determine the material parameters that have the greatest influence on the mat forming of CBPB. Therefore, three different particle types with different size parameters were prepared. Both the wood particle size and the cement/wood $(\mathrm{c} / \mathrm{w})$ ratio were varied. 
The results from this study will make it possible to identify relationships between the parameters of the wood-cement mixes and formation of mats via aerodynamic spreading, which will help create CBPB with specific density profiles.

\section{Materials and methods}

\subsection{Wood particle preparation}

The wood particles were made of Norway spruce (Picea abies (L.) Karst.). Three types of particles with different sizes were produced. After debarking and cutting, one part of the roundwood was chipped by a drum chipper. Those chips were then milled by a knife-ring flaker. Afterward, the particles were separated into fine particles (A), typically used for the surface layers in three-layered $\mathrm{PB}$, and coarse particles (B), which are used for core layers. A disc chipper was used to produce the third particle type. In this process, large particles with a high slenderness ratio (C), as the representative variant for core and surface layers, were produced. The size of the particles was determined with the image analysis system Camsizer (Retsch, Haan, Germany). Three measurements, each of $10 \mathrm{~g}$ (absolutely dry), were taken per particle type. In addition to the measured particle size parameters length and width, further characteristic parameters of the particles were calculated. The shape of the particle surface can be described by the ratio of length to width, whereby an aspect ratio of 1.0 represents a square surface. With an increasing ratio, the shape becomes rectangular. With the Camsizer it is not possible to calculate thickness as the third dimension of the particle. Assuming that the variance of the particle thickness was very low, the overlap of the cutting knife of $0.4 \mathrm{~mm}$ at particle production was used to calculate the surface and the volume of the particles. By knowing the volume and the density, it was possible to calculate the mass of the particles. Because the particles were from one single tree, the average dry density of $420 \mathrm{~kg} /$ $\mathrm{m}^{3}$ was used for the three particle types. In addition, the mass-related specific surface area (SSA) of the particles was calculated as the ratio of surface area $(s)$ and mass $(m)$ :

$S S A=\frac{S}{m}$

\subsection{Procedure for mat forming}

First, the mix of wood particles, cement and water was prepared. The ratio of water to cement was set at 0.45 for all variants. To calculate the required amount of water to add, the moisture content (MC) of the particles was determined. The calculated amount of water was added to the particles in a blender and mixed for 3 min. The cement was then added. Depending on the $\mathrm{c} / \mathrm{w}$ ratio $(1.9,2.6,3.3)$ the dry amount of wood particles and cement changed according to the desired $\mathrm{c} / \mathrm{w}$ ratio (either 1.9, 2.6, or 3.3). The complete mixture was stirred for another $5 \mathrm{~min}$. Three mixes of each variant were prepared for mat forming. Portland cement type CEM I 42.5 $\mathrm{R}$ was used for all cement-wood mixes. The experimental design for the mat forming is summarized in Table 1.

The experimental setup for mat forming via aerodynamic spreading consisted of a conveyor belt, which transported the wood-cement mixture to the blower. The blower was arranged below the conveyor belt. The particles were separated by airflow. The speed of the conveyor belt and the air velocity of the blower were the same for all trials. The particles dropped down on a four-meter long deposition area, which substituted for the transport caul of the particle mat. The air speed was adjusted so that the entire length of the deposition area was usable. The deposition area was static, so that the separation of particles could easily be determined by collecting the particles according to their spreading distance. Therefore, the deposition area was divided into 12 equally long sections of $33 \mathrm{~cm}$.

Table 1 Experimental design and number of analysed cement-wood particle mixtures

\begin{tabular}{|c|c|c|c|c|c|c|c|c|c|c|}
\hline Variant & Particle type & $\begin{array}{l}\text { Particle } \\
\text { MC [\%] }\end{array}$ & $\begin{array}{l}\text { Cement/ } \\
\text { wood } \\
\text { ratio }\end{array}$ & $\begin{array}{l}\text { Water/ } \\
\text { cement } \\
\text { ratio }\end{array}$ & Total mass & $\begin{array}{l}\text { Wood } \\
\text { mass (dry) } \\
{[\mathrm{g}]}\end{array}$ & Wood mass [g] & Cement mass [g] & Water mass [g] & $\mathrm{N}$ \\
\hline 1 & A & 3.6 & 1.9 & 4.5 & 500.0 & 131.8 & 136.5 & 250.7 & 112.8 & 3 \\
\hline 2 & A & 3.6 & 2.6 & 4.5 & 500.0 & 104.0 & 107.7 & 270.6 & 121.7 & 3 \\
\hline 3 & A & 3.6 & 3.3 & 4.5 & 500.0 & 85.8 & 88.9 & 283.5 & 127.6 & 3 \\
\hline 4 & B & 6.1 & 1.9 & 4.5 & 500.0 & 130.9 & 138.9 & 249.1 & 112.0 & 3 \\
\hline 5 & B & 6.1 & 2.6 & 4.5 & 500.0 & 103.5 & 109.8 & 269.1 & 122.5 & 3 \\
\hline 6 & B & 6.1 & 3.3 & 4.5 & 500.0 & 85.6 & 90.8 & 282.2 & 127.0 & 3 \\
\hline 7 & $\mathrm{C}$ & 6.6 & 1.9 & 4.5 & 500.0 & 131.0 & 139.7 & 248.5 & 143.1 & 3 \\
\hline 8 & $\mathrm{C}$ & 6.6 & 2.6 & 4.5 & 500.0 & 103.5 & 110.4 & 268.7 & 120.9 & 3 \\
\hline 9 & $\mathrm{C}$ & 6.6 & 3.3 & 4.5 & 500.0 & 85.5 & 91.2 & 282.0 & 126.8 & 3 \\
\hline
\end{tabular}




\subsection{Test procedures}

After spreading, the particles of each section were collected and their collective weight determined. For the investigation of the particle size in the Camsizer, the mixture had to be dried and sieved. By drying at $102{ }^{\circ} \mathrm{C}$, the particle-mixture changes its flow behaviour. While moist particles exhibited a high bridging effect, the dry particles showed a free-flowing behaviour. The MC was calculated by determining the mass before and after drying. The dust of the dried particles was sieved out with a mesh size of $0.16 \mathrm{~mm}$. Although the cameras in the Camsizer have a resolution of up to $30 \mu \mathrm{m}$, such small particles may cause incorrect particle size measurements. This is due to insufficient separation of the dust particles. After measuring the particle size, the variants with a c/w ratio of 1.9 and 3.3 were combusted at $1000{ }^{\circ} \mathrm{C}$ to determine the cement content. The sieved out dust was combusted together with the particles. The cement content was calculated from the mass of the mixture after ignition plus the loss on ignition of pure cement. The loss on ignition of pure cement was determined by drying and igniting cement samples from Portland cement type CEM I 42.5 R. The loss on ignition $\frac{\Delta w_{n, c}}{c}$ was calculated to be $1.63 \%$.

The effective residual cement content in the mixture can then be calculated according to Eq. 2 .

$c_{\text {sample }, \text { eff }}=c_{\text {sample }}\left(1-\frac{\frac{\Delta w_{n, c}}{c}}{\frac{w_{n}^{0}}{c}}\right)$

where $w_{n}^{0}$ is the chemically bound water at complete hydration of the cement quantity $c$.

The quotient $w_{n}^{0} / c$ varies between approx. 0.18 and 0.26 , depending on the composition of the cement (Powers and Brownyard 1946). As was the case in this study, the value 0.25 is often used. The procedure was very time-consuming $(24 \mathrm{~h})$ and there was only room for 9 sample holders in the muffle furnace. That is why only every second part of the deposition area (6 parts) of the variants 1, 3, 4, 6, 7, 9 was analysed $(\mathrm{N}=108)$.

Knowing the c/w ratio and the absolute dry density of Portland cement $\left(3100 \mathrm{~kg} / \mathrm{m}^{3}\right)$ and spruce $\left(420 \mathrm{~kg} / \mathrm{m}^{3}\right)$, it is possible to calculate the density of the cement-wood particle mixture:

$$
\rho_{\text {mix }}=\frac{m_{\text {mix }}}{\left(\frac{\frac{m_{\text {mix }}}{1+\frac{x}{w}}}{\rho_{\text {wood }}}\right)+\left(\frac{\frac{m_{\text {mix }}}{1+\frac{1}{\frac{\underline{c}}{w}}}}{\rho_{\text {cement }}}\right)}
$$

where $\rho$ is the dry density of wood or cement, $\rho_{\text {mix }}$ represents the density of the mixture of both, and $m$ is the mass of the mix. Using this calculated density and the previously determined particle volume and surface area, the mass and, subsequently, the SSA of the particles were calculated.

\section{Results and discussion}

\subsection{Size characterisation of the wood particles prior to mixing}

Table 2 and Fig. 1 show the results of the particle size measurements. Types A and B differ in the length of the particles because of the different size of the sieves used. Only a small deviation in width was observed. Because the same chipping process was used to produce types $\mathrm{A}$ and $\mathrm{B}$, the distribution of the width was almost comparable. The particles of type $\mathrm{C}$ were much longer and wider than types $\mathrm{A}$ and $\mathrm{B}$. Furthermore, the slenderness of type $C$ was higher than that of type A but nearly similar to that of type B. The variation was, for both length and width, higher at type $\mathrm{C}$ than at types $\mathrm{A}$ and $\mathrm{B}$ and indicates a lower homogeneity for type $\mathrm{C}$ particles in comparison to types A and B. With an aspect ratio of 2.48, particle type A had a squarer shape than types B and C. With increasing particle size, the surface area and mass increased and the SSA decreased.

\subsection{Mat forming characteristics-mass distribution}

Figure 2 shows the distribution of the wood-cement mixtures along the spreading distance as a function of the $\mathrm{c} / \mathrm{w}$ ratio for the three particle types. The distribution represents a logarithmic normal distribution with a
Table 2 Particle parameters calculated from mean particle length and width (standard deviation) of different wood particle types $(\mathrm{N}=3)$

\begin{tabular}{|c|c|c|c|c|c|c|c|}
\hline Particle type & $\begin{array}{l}\text { Particle count } \\
\text { per measure- } \\
\text { ment }\end{array}$ & $\begin{array}{l}\text { Length } \\
{[\mathrm{mm}]}\end{array}$ & $\begin{array}{l}\text { Width } \\
{[\mathrm{mm}]}\end{array}$ & Aspect ratio & $\begin{array}{l}\text { Surface } \\
\text { area }^{\mathrm{a}} \\
{\left[\mathrm{mm}^{2}\right]}\end{array}$ & $\begin{array}{l}\text { Mass }^{b} \\
{[\mathrm{mg}]}\end{array}$ & $\begin{array}{l}\text { SSA } \\
{\left[\mathrm{mm}^{2} / \mathrm{mg}\right]}\end{array}$ \\
\hline A $\quad \bar{X}[\mathrm{~mm}]$ & 695,120 & $3.18(1.79)$ & $1.28(0.74)$ & 2.48 & 11.71 & 0.68 & 17.22 \\
\hline $\mathrm{B} \quad \overline{\mathrm{X}}[\mathrm{mm}]$ & 337,866 & $5.38(2.48)$ & $1.20(0.70)$ & 4.48 & 18.18 & 1.08 & 16.83 \\
\hline $\mathrm{C} \quad \overline{\mathrm{X}}[\mathrm{mm}]$ & 472,773 & $10.43(7.54)$ & $2.20(1.61)$ & 4.74 & 56.00 & 3.85 & 14.55 \\
\hline
\end{tabular}

${ }^{\mathrm{a}}$ With thickness $=0.4 \mathrm{~mm}$

${ }^{\mathrm{b}}$ With wood density $=420 \mathrm{~kg} / \mathrm{m}^{3}$ 
Fig. 1 Particle length (a) and width (b) of three different wood particle types (dotted line: type A; dashed line: type B; continuous line: type $\mathrm{C}$ )
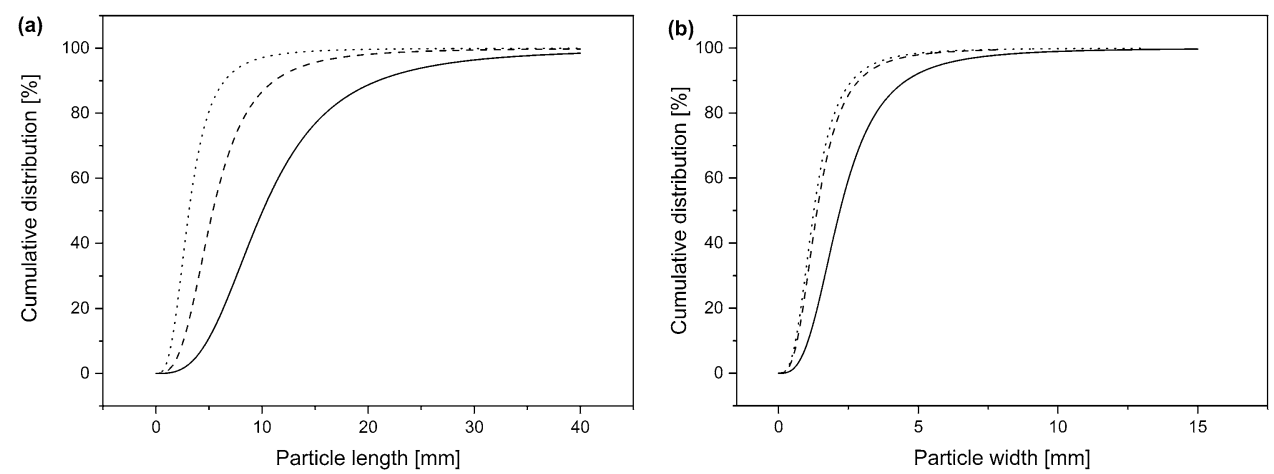

(a)

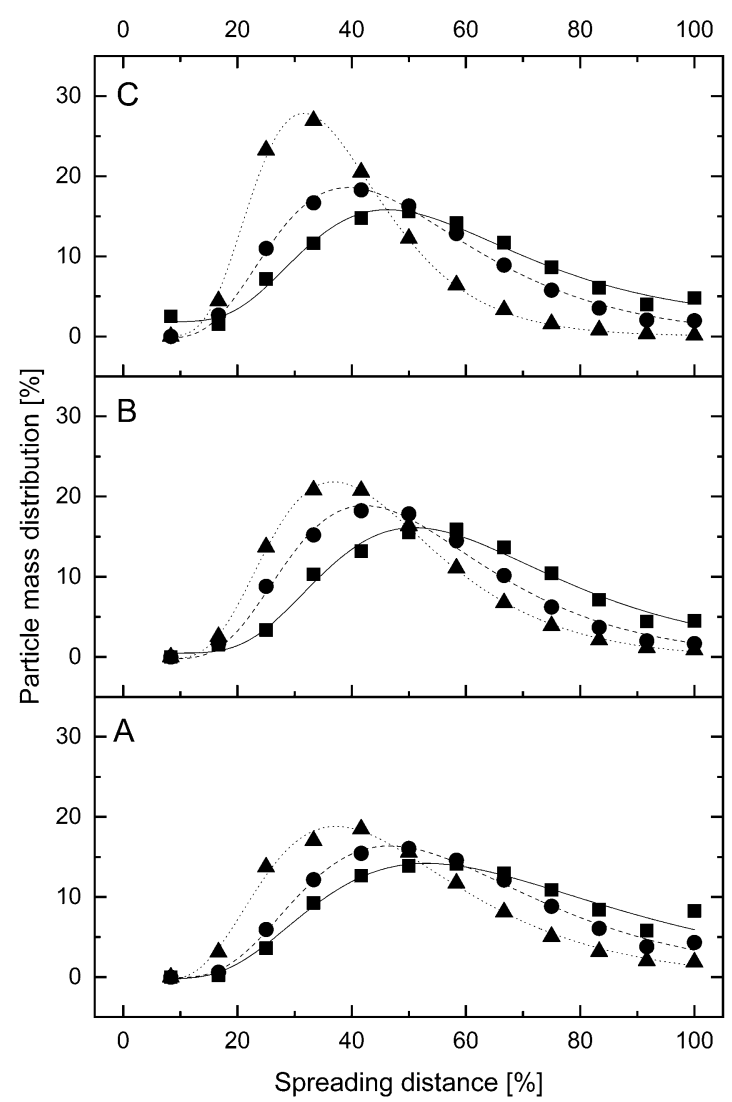

(b)

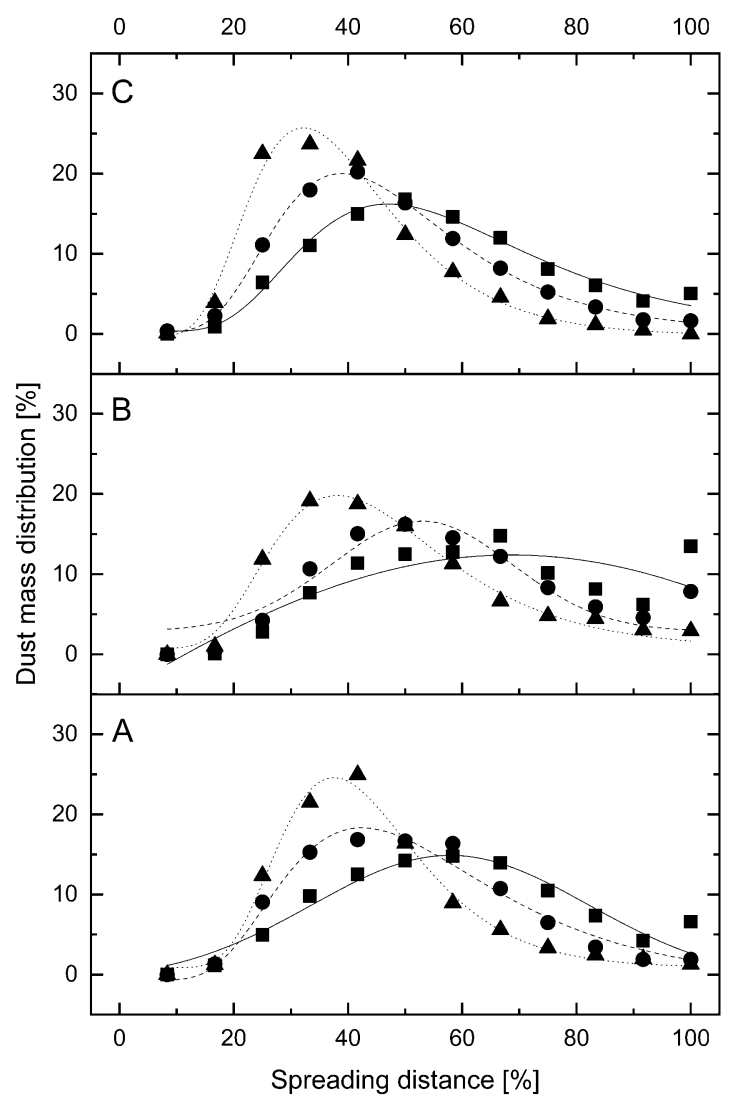

Fig. 2 Mass distribution of cement-wood-mixture over spreading distance by aerodynamic mat forming as a function of the c/w ratio and the wood particle size (a particles without dust; $\mathbf{b}$ sieved out dust)

correspondence value $\mathrm{R}^{2}>0.95$. The mean spreading distance of the particles changed with the mean particle size and the cement content. With increasing particle size from particle type A to type $\mathrm{C}$, the mean distance decreased (Table 3). By increasing the cement content, more material accumulated at the beginning of the measuring area. It was expected that because of the high cement density, the mass of the cement-loaded wood particles would increase. It can be concluded that large heavy particles (variant 9) drop down sooner than small light ones (variant 1).

The change of the spreading distance with increasing cement content was similar for the three particle types. By increasing the cement content from $\mathrm{c} / \mathrm{w} 1.9$ to 3.3 , the mean spreading distance decreased by $28-32 \%$ (Table 2). It was expected that a particle type with a large SSA would show a different change in flight characteristics after loading with 
Table 3 Measured and calculated particle parameters and mean spreading distance with respect to particle type and c/w ratio (in italics: real values were calculated by means of the analysed variants c/w 1.9 and 3.3)

\begin{tabular}{|c|c|c|c|c|c|c|c|c|c|c|c|c|c|}
\hline \multirow[t]{2}{*}{ Particle type } & \multirow[t]{2}{*}{$\mathrm{c} / \mathrm{w}$} & \multicolumn{2}{|c|}{$\begin{array}{l}\text { Cement con- } \\
\text { tent }[\%]\end{array}$} & \multirow[t]{2}{*}{$\begin{array}{l}\text { Length } \\
{[\mathrm{mm}]}\end{array}$} & \multirow[t]{2}{*}{$\begin{array}{l}\text { Width } \\
{[\mathrm{mm}]}\end{array}$} & \multirow[t]{2}{*}{$\begin{array}{l}\text { Surface } \\
\text { area }\left[\mathrm{mm}^{2}\right]^{\mathrm{a}}\end{array}$} & \multicolumn{2}{|c|}{$\begin{array}{l}\mathrm{SSA} \\
{\left[\mathrm{mm}^{2} / \mathrm{mg}\right]}\end{array}$} & \multicolumn{2}{|c|}{$\begin{array}{l}\text { Particle mass } \\
{[\mathrm{mg}]}\end{array}$} & \multicolumn{2}{|c|}{$\begin{array}{l}\text { Particle density }[\mathrm{kg} / \\
\left.\mathrm{m}^{3}\right]\end{array}$} & \multirow{2}{*}{$\begin{array}{l}\text { Mean spread- } \\
\text { ing distance } \\
{[\%]}\end{array}$} \\
\hline & & Set & Real & & & & Set & Real & Set & Real & $\mathrm{Set}^{\mathrm{b}}$ & Real & \\
\hline \multirow[t]{3}{*}{ A } & 1.9 & 65.5 & 61.7 & 3.02 & 1.29 & 11.24 & 7.45 & 7.99 & 1.51 & 1.41 & 968.65 & 902.17 & 53.11 \\
\hline & 2.6 & 72.2 & - & 2.96 & 1.26 & 10.84 & 6.50 & 6.99 & 1.67 & 1.53 & 1118.13 & 1025.59 & 46.60 \\
\hline & 3.3 & 76.7 & 73.2 & 2.79 & 1.17 & 10.33 & 5.84 & 6.38 & 1.77 & 1.62 & 1248.02 & 1143.05 & 37.24 \\
\hline \multirow[t]{3}{*}{ B } & 1.9 & 65.5 & 63.0 & 4.77 & 0,94 & 13.54 & 7.79 & 8.17 & 1.74 & 1.66 & 968.65 & 923.51 & 50.91 \\
\hline & 2.6 & 72.2 & - & 4.33 & 0,92 & 12.17 & 6.83 & 7.19 & 1.78 & 1.68 & 1118.13 & 1055.14 & 42.20 \\
\hline & 3.3 & 76.7 & 74.2 & 4.20 & 0,89 & 11.55 & 6.19 & 6.58 & 1.87 & 1.75 & 1248.02 & 1173.19 & 36.78 \\
\hline \multirow[t]{3}{*}{$\mathrm{C}$} & 1.9 & 65.5 & 63.2 & 5.97 & 1.63 & 25.54 & 6.77 & 7.06 & 3.77 & 3.62 & 968.65 & 929.34 & 46.23 \\
\hline & 2.6 & 72.2 & - & 5.66 & 1.55 & 23.31 & 5.94 & 6.17 & 3.92 & 3.77 & 1118.13 & 1073.69 & 39.44 \\
\hline & 3.3 & 76.7 & 75.2 & 6.23 & 1.67 & 27.13 & 5.22 & 5.42 & 5,19 & 5.01 & 1248.02 & 1203.27 & 31.64 \\
\hline
\end{tabular}

${ }^{\mathrm{a}}$ With thickness $=0.4 \mathrm{~mm}$

${ }^{\mathrm{b}}$ With wood density (absolutely dry) $=420 \mathrm{~kg} / \mathrm{m}^{3}$; cement density $=3.100 \mathrm{~kg} / \mathrm{m}^{3}$

cement to those particle types with a small SSA. For PB, the adhesive content per unit particle surface area is higher for particles with a small SSA than for particles with a larger SSA at a given adhesive content per unit of absolutely dry mass of particles (Hill and Wilson 1978; Dunky 1988; Medved and Resnik 2010). Therefore, particle type $C$ with a smaller SSA should bind more cement, resulting in a greater increase in mass and volume and should consequently drop down earlier.

Consequently, the speed of the caul or of the air stream should be adjusted when changing the $\mathrm{c} / \mathrm{w}$ ratio of the mixture. At unchanged speed, the mat would be much thicker with a c/w ratio of 3.3 rather than 1.9 after the same length of time. For PB, the spreading distance increases almost linearly with the air velocity (Rackwitz and Obermaier 1962). To guarantee the same spreading and, thus, distribution of the particles in the mat height before pressing, the speed of the caul, or rather the speed of the air stream and the mass flow, has to be raised with increasing cement content. In practice, the mass flow is not changed much and only the speed of the caul is adjusted depending on the target thickness of the panel. The mass flow is controlled by a matweighing system.

The measuring of the dust content is presented in Fig. 2. The mass-distribution of the sieved out particles followed the distribution of the complete mix. This indicates that the dust particles were components of the particles transported over the spreading distance and were separated when they dropped down or during drying. By weighing the dust, the content for each variant could be calculated. While the dust content showed no difference between a c/w ratio of 1.9 and 2.6, it increased strongly with a c/w ratio of 3.3 for all particle types. That increase was greatest for particle type C. After changing the cement content, the dust content of particle types A and B was nearly the same for all three $\mathrm{c} / \mathrm{w}$ ratios. In contrast, particle type $\mathrm{C}$ showed a much lower dust content at a c/w of 1.9 and 2.6 than at a c/w of 3.3. It seems that the lower cement contents were high enough to cover the wood particles with cement. With a c/w ratio above 3.3, the cement coated the particles in several layers. After drying, only the cement on the surface of the particles remained.

\subsection{Mat forming characteristics—distribution of particle size}

As expected, the wood particle size decreased with increasing spreading distance (Fig. 3). According to Thoemen et al. (2010), the particle size is the predominant separating effect when aerodynamic formers are used for PB. The effect of the horizontal airflow is to blow the finest particles to the end of the caul, while the coarse particles drop down almost vertically. No differences were observed concerning the progression of the spreading distribution curve with changing $\mathrm{c} / \mathrm{w}$ ratio of the same particle type. Therefore, the three variants of one particle type were consolidated. The distribution of the particle size represents an exponentially decreasing distribution with a correlation factor $\mathrm{R}^{2}>0.95$ for particle type $\mathrm{C}$. The correlation factor for the length of particle type $\mathrm{B}$ is also $\mathrm{R}^{2}>0.95$, but for the width it is only 0.81 . For particle type $\mathrm{A}$, no change in particle size along the spreading distance could be determined. The separation effect of the particle size differed depending on the particle type. The more heterogeneous the particles, the greater the effect. That is why particle type $\mathrm{C}$ showed the highest regression coefficient. For type A, with very small and more homogeneous particles, no difference in particle size over the spreading distance was determined. In addition, according to Rackwitz and Obermaier (1962), particles with a larger ratio of 
Fig. 3 Particle length (a) and width (b) distribution of cement-wood mix over spreading distance by aerodynamic mat forming as a function of the $\mathrm{c} / \mathrm{w}$ ratio and the wood particle type (error bars illustrate the different $\mathrm{c} / \mathrm{w}$ ratios)

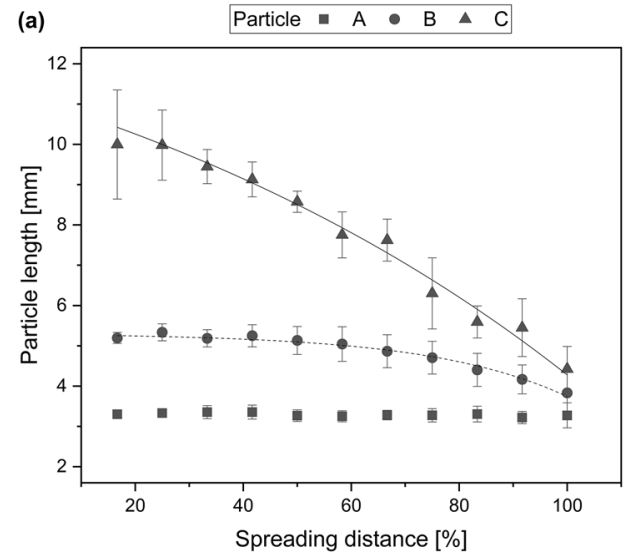

(b) $\quad$ Particle type $\triangle A \bullet B \triangle C$

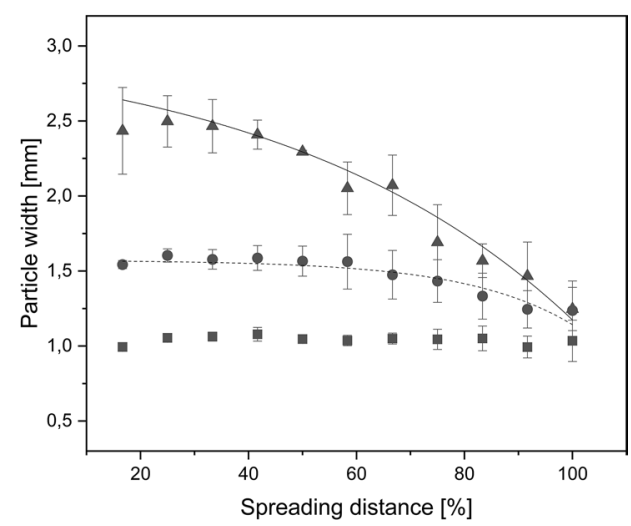

length to width tend to self-rotate in the air flow and thus the separation effect is greater. The state of motion due to selfrotation is obviously more stable than without, because the rotating particles have a higher energy content. That could explain why the distribution was much more heterogeneous for type B than for type A. It must be noted that the particle sizes decreased in contrast to the particles without cement. Despite the dust separation, the content of fine particles in the wood-cement-mix was still higher than without cement. Since both the particles with and without cement were dried before measuring, the influence of shrinkage processes can be excluded.

\subsection{Mat forming characteristics-distribution of cement content}

The theoretical cement content at a c/w ratio of 1.9 and 3.3 was $65.5 \%$ and $76.7 \%$, respectively. The measured cement content for a c/w ratio of 1.9 and 3.3 at the different particle types amounted to $62.6 \%$ and $74.2 \%$, respectively. Between the particle types, only negligible differences were observed.

The results of the distribution of the cement content over the spreading distance are presented in Fig. 4. At a c/w ratio of 1.9, the cement content increased with the spreading distance at all variants (Fig. 4a). For particle types A and C, the difference between the cement content at the beginning and at the end of the measuring section amounted to $10 \%$, while the increase in cement content was only $6 \%$ for particle type B.

For the particles loaded with higher cement content, no or only small changes were observed from one end of the measured distance to the other (Fig. 4b). The cement content of the mixture with particle type $\mathrm{C}$ increased slightly, around $5 \%$, until it stagnated. For types A and B, the cement content did not change over the spreading distance.

The difference in cement content distribution of the different c/w ratios can most probably be explained by a possible loading of the wood particles with the cement grains. With a c/w ratio of 1.9 , fewer cement grains are present in the mix and most of them were able to stick to the surface of the wood particles, while when increasing the $\mathrm{c} / \mathrm{w}$ ratio up to 3.3 , more cement grains were not bonded to the wood surface.

It can be concluded that the loading of the particles with cement essentially did not change when using different particle types, but within one particle type, the loading with
Fig. 4 Distribution of the cement content of three different particle fractions at different $\mathrm{c} / \mathrm{w}$ ratio $(\mathbf{a} \mathrm{c} / \mathrm{w}$ ratio $1.9 ; \mathbf{b}$ c/w ratio 3.3) over spreading distance by aerodynamic mat forming

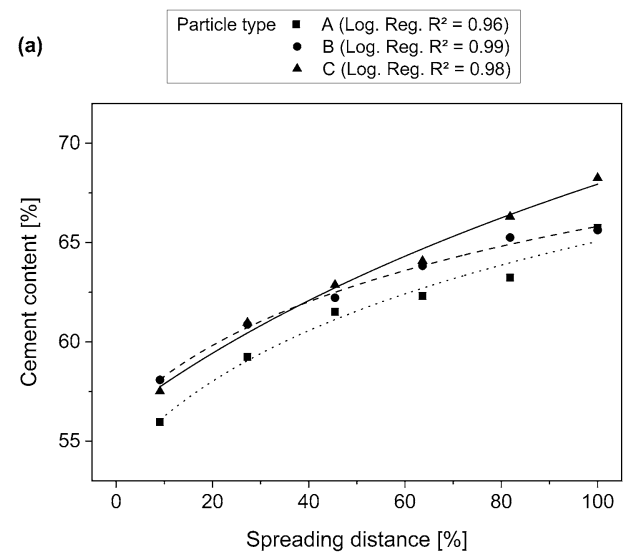

(b)

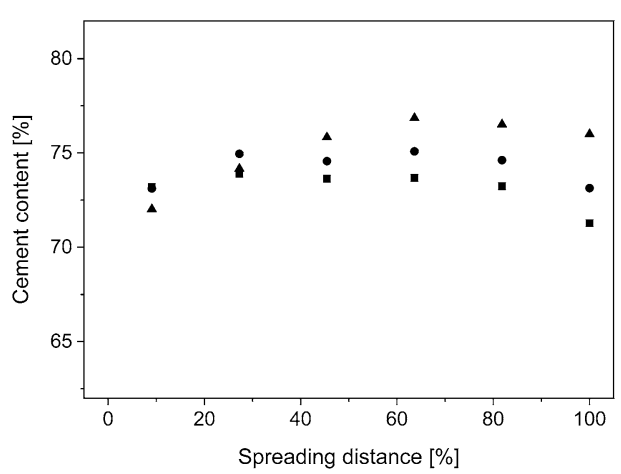


cement differed depending on the particle size. According to the correlation in Fig. 5, the cement content decreased with increasing particle size for particle type $\mathrm{C}$ at a c/w ratio of 1.9. Because of the larger surface area of the fine particles, their cement load is much higher, similar to PB (Dunky 1988). That is the reason why core layers and surface layers are typically glued separately for PB. Because of the small variation in particle size distribution of types $A$ and $\mathrm{B}$, no distinct correlation with the cement content could be detected for CBPB.

\subsection{Parameters influencing air spreading}

In Table 3, the characteristic parameters of the three particle types with different cement contents are listed. The real values were calculated from the measured cement content, while the set values resulted from the $\mathrm{c} / \mathrm{w}$ ratios. Because the cement content of the particles with a c/w ratio of 2.6 was not further investigated, the calculation of the missing values was based on the average of the existing values per particle type.

In Fig. 6, the particle parameters were correlated with the mean spreading distance. For the correlation, only the analysed variants with a c/w of 1.9 and 3.3 were used. For the combination of size and mass-represented by the density and the SSA- a correlation with the mean spreading distance was observed. With increasing density, the spreading distance decreases linearly. Conversely, the spreading distance increased linearly with increasing SSA. The mean mass and the size of the particle mixes showed no correlation with the mean spreading distance. However,

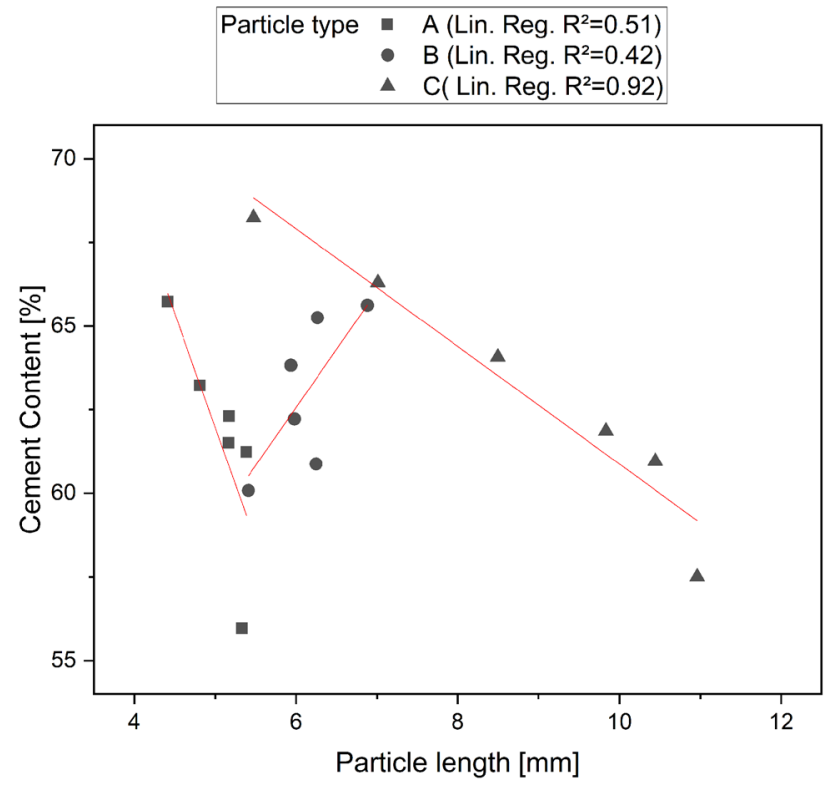

Fig. 5 Correlation of cement content and particle size if only the values within one c/w ratio were considered, correlations were apparent. Particle size and particle mass decreased with increasing distance.

Next to the dependence of the mean spreading distance on the particle parameters, Fig. 7 shows the change in density, mass, surface area and SSA of the particles with increasing spreading distance of the three particle types. In contrast to the spreading distance, such dependencies were less obvious. Especially for particle type A, the influence of the particle parameters on the spreading distance was very small. Particle type B was only slightly correlated with slight tendencies of a dependence of the spreading distance on the analysed particle parameters. This may be due to the homogeneity of the size of the wood particles, which inhibits a stronger separation over the spreading distance. With other process parameters, such as, for example air velocity, the separation would be more obvious.

For particle type $\mathrm{C}$ with a heterogeneous particle size, the separation was more defined. As already noted, the surface area decreased linearly (c/w 3.3) or followed a Gaussian amplitude distribution (c/w 1.9) with increasing spreading distance. The same applied to particle type B. Furthermore, particle type A showed a linear decrease in the particle size with increasing distance for $\mathrm{c} / \mathrm{w} 3.3$. Therefore, the same relationship existed here as for PB (Thoemen et al. 2010). For the mass of the particles, a similar effect was observed. The lighter particles were transported a longer distance than the heavier ones. Only one linear regression was found for particle type $\mathrm{C}$, with a c/w of 3.3. The other distributions again followed a Gaussian amplitude. In contrast, the density increased linearly over almost the entire spreading distance. This is also in contrast to the results of the mean spreading distance of the different particle types. The linear relationship appeared only for those variants with a notable change in the cement content (Fig. 4). In spite of the increasing density, the SSA hardly changed. After an exponential drop, the SSA increased linearly with increasing spreading distance.

It seems like neither the size of the particle nor its mass was the controlling factor of the spreading distance. The particle properties influencing the separation of cementloaded wood particles the most are a combination of both size and mass, associated with particle density, respectively SSA.

Two opposing force vectors act upon any particle situated in a rising column of air. The airstream exerts an upward force on the particle, called "drag". The magnitude is directly proportional to the surface area of the particle. Resisting this vertical drag force is the gravitational force due to the mass of the particle. The vector resulting from these two forces determines whether the particle will rise, fall or float in the airstream. 
Fig. 6 Correlation between particle properties and mean spreading distance for wood particle cement mixtures by aerodynamic mat forming of wood particle-cement mixes

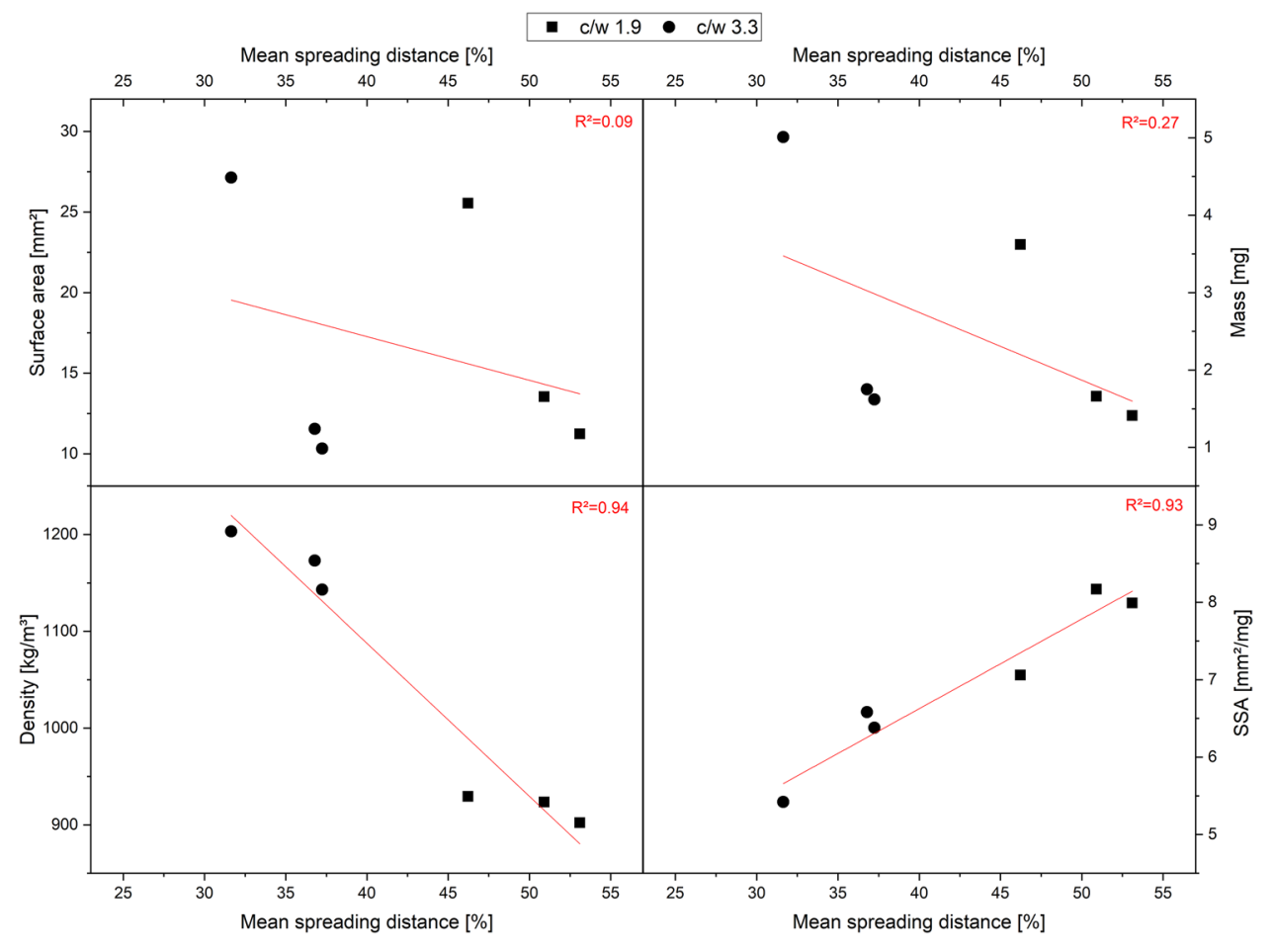

\section{Conclusion}

The spreading distance of cement-loaded wood particles in an aerodynamic separation mat-forming process depends significantly on the parameters of particle size and c/w ratio. With increasing spreading distance, the particle size and particle mass decrease. The more heterogeneous the particle size distribution, the stronger the separation.

With increasing $\mathrm{c} / \mathrm{w}$ ratio, the overall spreading distance decreases, due to the higher mass of the mixture.
To guarantee the same mat height with increasing cement content, the speed of the conveyor belt must be increased. If this is not taken into account, excessive compaction of the CBPB with the same target thickness will inevitably result.

The cement content increases and the particle size decreases over the spreading distance. Therefore, it can be concluded that particles with a large surface area are able to bind more cement, as is the case with PB. This assumption can be supported by the change in particle
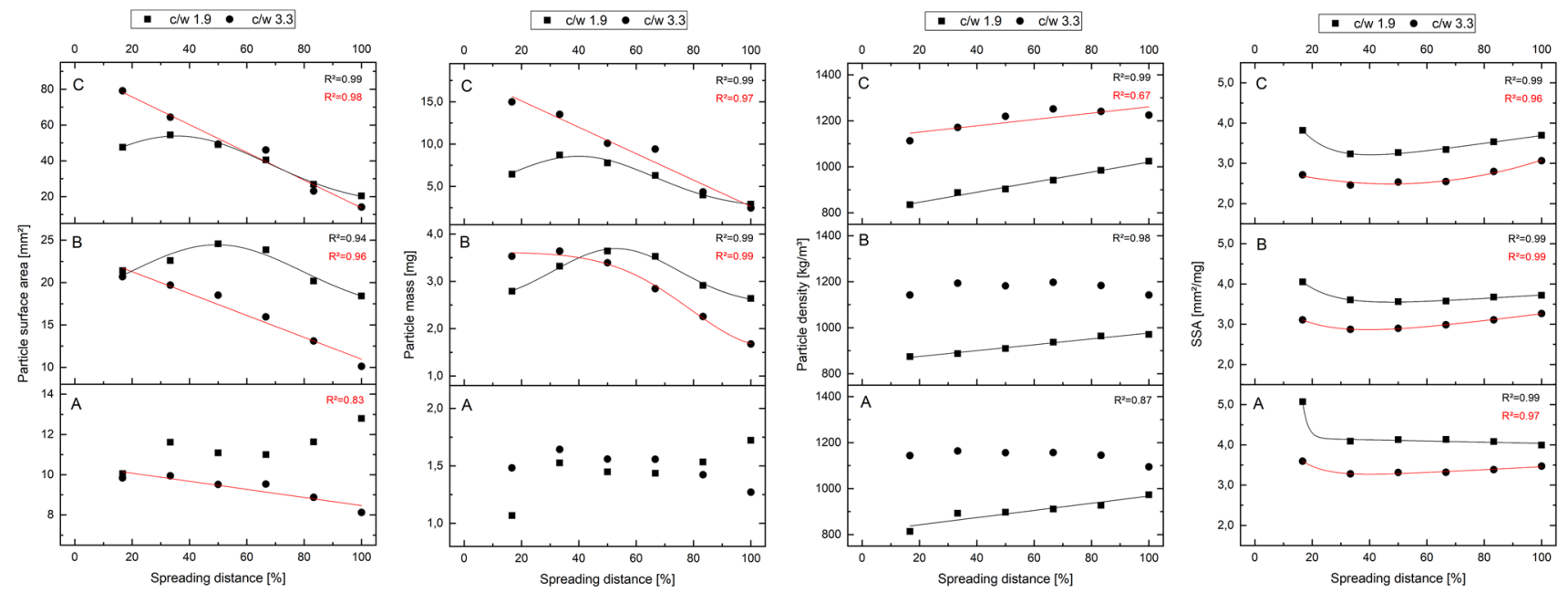

Fig. 7 Distribution of the particle parameters: density, surface area, mass and specific surface at a different c/w ratio and particle type (A, B, C) over the spreading distance by aerodynamic mat forming 
density and SSA. Although the particles become smaller and lighter with increasing spreading distance, the density and the SSA increase. This indicates that the smaller particles become heavier since they proportionally bind more cement than larger ones.

For controlling the mat forming process of CBPB, the density and the SSA seem to be suitable parameters. Both allow the aerodynamic mat forming to be adapted by changing particle size and cement content. In a production setting, the content of the bonding agent must be adapted, too, with changing particle size. As mentioned before, the spreading distance increases linearly with the air velocity.

A linear correlation exists between the mean spreading distance and the density and SSA of the particles. This allows the mat weight to be kept constant by controlling the air speed to accommodate changes in particle density and particle SSA. An adaptation of the caul speed is rather undesired, since the time from mixing to pressing is specified by the CBPB producers, depending on the recipe. To establish a correlation of air velocity and the distribution of particle-cement blends, further investigations are necessary.

In consideration of the two types of mat forming processes used for CBPB, the following conclusions for the mat forming of three-layered CBPB can be drawn for the Eltomation Process with one wood-cement mixture. The use of a heterogeneous wood particle size (e.g., particle type $C$ ) leads to a separation of particle size and mass over the spreading distance. The generated CBPB would be characterised by coarser particles and a lower cement content in the core layer in comparison to finer particles and a higher cement content in the outer layers. In this case, the density profile shows density peaks in the outer layers and a density minimum in the core, according to the linear density increase by increasing spreading distance. This requires two blowers working in opposite directions.

Acknowledgements The underlying investigations of this article were part of a R\&D project funded by the German Federal Ministry of Economics and Energy (BMWi) at the decision of the German Bundestag (KF2178735WZ4)

Funding Open Access funding enabled and organized by Projekt DEAL.

Open Access This article is licensed under a Creative Commons Attribution 4.0 International License, which permits use, sharing, adaptation, distribution and reproduction in any medium or format, as long as you give appropriate credit to the original author(s) and the source, provide a link to the Creative Commons licence, and indicate if changes were made. The images or other third party material in this article are included in the article's Creative Commons licence, unless indicated otherwise in a credit line to the material. If material is not included in the article's Creative Commons licence and your intended use is not permitted by statutory regulation or exceeds the permitted use, you will need to obtain permission directly from the copyright holder. To view a copy of this licence, visit http://creativecommons.org/licenses/by/4.0/.

\section{References}

Boehme C (1992) Die Bedeutung des Rohdichteprofils für MDF [The importance of the density profile for MDF]. Holz Roh Werkst 50(1):18-24

Dunky M (1988) Einfluss der Spangrößenverteilung auf den Beleimungsgrad der Späne [Influence of particle size distribution on the degree of gluing of particles]. Holzforschung und Holzverwertung 40(6):126-133

Fan M, Dinwoodie JM, Bonfield PW, Breese MC (1999) Dimensional instability of cement bonded particleboard: behaviour of wood chips from various stages of manufacture of CBPB. J Mater Sci 34(8):1729-1740

Fan M, Bonfield P, Dinwoodie J (2006) Nature and behaviour of cement bonded particleboard: structure, physical property and movement. J Mater Sci 41(17):5666-5678

Frybort S, Mauritz R, Teischinger A, Müller U (2008) Cement bonded composites-a mechanical review. BioResources 3(2):602-626

Hill M, Wilson J (1978) Particleboard strength as affected by unequal resin distribution on different particle fractions. For Prod J 28(11):44-48

Jorge FC, Pereira C, Ferreira JMF (2004) Wood-cement composites: a review. Holz Roh Werkst 62(5):370-377

Medved S, Resnik J (2010) Determination of share of adhesive on particles with FT-IR spectroscopy. Wood Res 55(1):101-109

Moslemi AA (1999) Emerging technologies in mineral-bonded wood and fiber composites. Adv Perform Mater 6(2):161-179

Niemz P, Sonderegger W (2017) Holzphysik. Physik des Holzes und der Holzwerkstoffe [Wood physics. Physic of wood and woodbased panels]. Carl Hanser Press, Munich, pp 138-163

Pampel H, Schwarz H-G (1979) Technologie und Verfahrenstechnik zementgebundener Spanplatten [Technology and process engineering of cement-bonded particleboard]. Holz Roh Werkst 37:195-202

Plath E, Schnitzler E (1974) Das Rohdichteprofil als Beurteilungsmerkmal von Spanplatten [The density profile as assessment characteristic of particleboards]. Holz Roh Werkst 32:443-449

Powers TC, Brownyard TL (1946) Studies of the physical properties of hardened portland cement paste. J Proc 43(9):101-132

Rackwitz G, Obermaier M (1962) Sifting of wood particles-part 1: foundations of sifting in a horizontal air-flow. Holz Roh Werkst 20(1):27-38

Saunders A, Davidson E (2014) Cement Boards 101. Glob Cement Mag (January):32-38

Schulte M, Frühwald A (1996) Shear modulus, internal bond and density profile of medium density fibre board (MDF). Holz Roh Werkst 54(1):49-55

Schwarz H-G, Wentworth R, Eilmus G (1994) The new age of inorganic-bonded wood compositions in north America. In: WSU (ed) 28th symposium particleboard/composite materials, pp 143-152

Soiné H (1995) Holzwerkstoffe: Herstellung und Verarbeitung. Platten, Beschichtungsstoffe, Formteile, Türen, Möbel [Wood-based materials. Manufacturing and processing; boards, coatings, mouldings, doors, furniture]. DRW-Press, Leinenfelden-Echterdingen, pp $47-50$

Thoemen H, Irle M, Sernek M (eds) (2010) Wood-based panels. An introduction for specialists. Brunel Univ. Press, London, pp 33-36

van Elten GJ (2006) Cement bonded particle board (CBPB) and wood strand cement board (ELTOBOARD): production, properties and applications. In: 10th International inorganic-bonded fiber composites conference, pp 49-58 
Wong M, Zhang M, Wang Q, Kawai S (1999) Formation of the density profile and its effects on the properties of particleboard. Wood Sci Technol 33:327-340
Publisher's Note Springer Nature remains neutral with regard to jurisdictional claims in published maps and institutional affiliations. 